\title{
ALGUNAS NOTAS SOBRE EL CONCEPTO DE OBJECIÓN DE CONCIENCIA*
}

\author{
SOME NOTES ABOUT THE CONCEPT \\ OF CONSCIENTIOUS OBJECTION
}

\section{ÍNIGO ÁlVAREZ GÁlVEZ ${ }^{* *}$}

\section{RESUMEN}

Existe todavía un debate abierto acerca de la objeción de conciencia. Buena parte de la discusión versa no sólo sobre el fundamento de la objeción de conciencia, sino también sobre su mismo concepto (y tiene que ver con preguntas tales como quién puede ejercerla, cuándo o cómo). El propósito del presente trabajo es el de contribuir a este debate aportando algunas ideas sobre la manera más adecuada de definir la objeción de conciencia.

Palabras clave: Objeción de conciencia, conciencia, desobediencia civil, deber jurídico, deber moral.

\section{ABSTRACT}

There is still an open debate on conscientious objection. Much of the discussion is not only about the foundation of conscientious objection, but also about the very concept of it (and it has to do with some questions such as who can exercise it, when or how). The purpose of this article is to contribute to this debate by providing some ideas on the most appropriate way to define conscientious objection.

Keywords: Conscientious objection, conscience, civil disobedience, legal duty, moral duty.

Recibido: 11.04.17. Aceptado: 15.06.17.

* El presente trabajo es producto del proyecto de investigación Fondecyt Regular 1160602, titulado "Representaciones discursivas sobre derechos y deberes profesionales, institucionales y rol del Estado, relacionadas con la objeción de conciencia sanitaria y despenalización de la interrupción voluntaria del embarazo, por tres causales en Chile".

** Doctor en filosofía, Facultad de Filosofía y Humanidades, Universidad de Chile, Santiago, Chile.Correo: ialvarezg@u.uchile.cl 


\section{UNA DEFINICIÓN DE OBJECIÓN DE CONCIENCIA}

$\mathrm{N}$ O ES FÁCIL DECIR en qué consiste la objeción de conciencia. Como tantos otros términos de nuestro lenguaje, esta locución posee varios defectos (ambigüedad, vaguedad, carga emotiva) que dificultan la elaboración de una definición clara y precisa. Fijarnos en el uso habitual que los hablantes hacen de la expresión, tal como haremos aquí, es una de las maneras de afrontar estos defectos. En el presente trabajo consideraremos en particular el ámbito jurídico, que es uno de los ámbitos en el que es más frecuente insertar la cuestión de la objeción de conciencia y donde se ha desarrollado, en consecuencia, una amplia literatura sobre la cuestión.

En términos generales, los juristas han venido concibiendo este comportamiento como una forma de desobediencia al Derecho basada en razones morales. Así, por ejemplo, Gascón la define como "aquel incumplimiento de un deber jurídico motivado por la existencia de un dictamen de conciencia, que impide observar el comportamiento prescrito y cuya finalidad se agota en la defensa de la moralidad individual, renunciando a cualquier estrategia de cambio político o de búsqueda de adhesiones" (Gascón, 1990, p. 85).

Es habitual, además, que se planteen ciertas cuestiones típicas, como la relativa a la confusión de la objeción de conciencia con otras figuras afines o la de su finalidad política. La misma autora citada recuerda algunas clasificaciones sobre los tipos de desobediencia al Derecho, como la de Passerin D’Entreves (1976), Garzón Valdés (1981) o Malem (1988). Por descontado, cada clasificación es tributaria del particular gusto del autor, que se manifiesta en la elección de un determinado criterio; pero más allá de mayor o menor acierto de estas propuestas, de inmediato podemos darnos cuenta de las dificultades que surgen tan pronto como se intenta precisar la figura de la objeción de conciencia: ¿es una forma de desobediencia civil? ¿exige

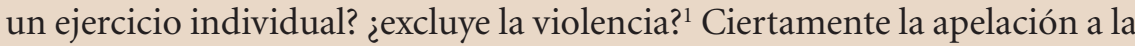
conciencia (moral) parece ser un elemento ineludible y es igualmente claro que se desobedece alguna norma del sistema. Pero podemos preguntarnos: ¿quién las desobedece?, ¿qué normas desobedece?, ¿cuántas desobedece?,

\footnotetext{
${ }^{1}$ Se trata de cuestiones que han sido puestas de manifiesto en numerosas ocasiones. Véase, por ejemplo, López (2002), quien considera, entre otras cosas, que la objeción de conciencia y la desobediencia civil son dos formas diferentes de desobediencia: "No se puede entender que una de estas figuras sea manifestación de la otra, ya que ambas participan de la condición de tipo dentro de un género más amplio, la desobediencia al Derecho" (López, 2002, p. 319).
} 
¿cómo lo hace?, ¿por qué y para qué? Permítasenos distinguir alguno de estos aspectos para mayor claridad en la exposición.

\section{EL OBJETIVO DE LA OBJECIÓN: LA DEFENSA DE LA PROPIA CONCIENCIA}

Cuando, en nuestras conversaciones cotidianas, decimos que alguien ejerció la objeción de conciencia, no queremos decir que lo que pretende tal sujeto es oponerse a todo el sistema. Al contrario, nos parece extraño pensar que las consideraciones morales puedan ser tales que nos impulsen a querer abatir o erradicar por completo el orden normativo. En esos casos, consideramos que lo más probable es que la motivación no sea, ni sólo ni principalmente, moral, y no solemos aplicar la locución 'objeción de conciencia' a esta conducta. El objetor de conciencia, en contraste, se ve impulsado por estas consideraciones morales que lo enfrentan a una o unas determinadas normas, pero no al sistema en total. Desobedece, desde luego, pero acepta el sistema (y, por cierto, el castigo, cuando lo hay) ${ }^{2}$. Su comportamiento, pues, no es un ataque al Derecho, sino una defensa de sí mismo, de su integridad moral ${ }^{3}$.

\footnotetext{
${ }^{2}$ Uno de los tantos ejemplos que se pueden presentar lo encontramos, en España, en el caso de la STC 15/82, en el que el objetor pedía que se aplazara su incorporación a filas hasta que se promulgase la ley reguladora de la objeción al servicio militar, lo que indica que dicho sujeto, primero, apelaba a una ley cuyo sentido era afirmar la existencia del deber militar y, segundo, deseaba conformar su conducta al sistema jurídico, es decir, aceptaba, en definitiva, el orden establecido. El Tribunal Constitucional, por cierto, falló a su favor; como también lo hizo en un caso similar (STC 35/85) en el que el objetor (en periodo de reserva militar) solicitaba el aplazamiento de las revistas anuales hasta que la Comisión Nacional de Objeción de Conciencia resolviera su situación como objetor, petición en la que podemos apreciar, de nuevo, que lo que desea el objetor es someterse al sistema jurídico y no destruirlo. Sobre la aceptación del castigo los casos también son numerosos: sólo por citar uno de ellos, en mayo de 2015, Amnistía Internacional se refería al caso de un objetor surcoreano que se había negado a hacer el servicio militar, pero que ni pretendía escapar de la pena de cárcel a la que sabía que estaba destinado, ni se negaba a cumplir con cualquier otro deber que le pudiera ser impuesto.

${ }^{3}$ Algo que ha sido puesto de manifiesto en muchas ocasiones, así se hable de motivos religiosos, éticos, morales, axiológicos o de justicia (Aparisi y López, 2006, p. 39) o de "una convicción moral, ideológica o religiosa" (Ortega, 1999, p. 122). Hay que observar, no obstante, que aunque hablamos de la integridad moral del individuo que objeta (volveremos sobre ello en un apartado posterior) eso no impide que en algunos supuestos, por ejemplo en los casos de menores de edad, la conciencia parezca ser no (o no sólo) la del menor, sino la de los padres (podemos recordar el caso de la STC 28/14, en el que los padres ejercieron la objeción de conciencia a la asignatura 'educación para la ciudadanía, cuyo destinatario era su hijo; objeción que fue, por cierto, reconocida en el TSJ de Andalucía y anulada por el Tribunal Supremo).
} 
Aquí puede también marcarse una diferencia con la desobediencia civil si se entiende que en ésta, aun no cuestionándose todo el sistema, lo que se pretende es modificar las normas ${ }^{4}$. En el terreno práctico, por cierto, esa diferencia puede ser sutil, pues el que tiene como objetivo cambiar la norma, muchas veces se fundamenta en similares motivos de conciencia; y el que tiene como objetivo proteger su conciencia desea también con frecuencia que la norma cambie ${ }^{5}$.

\section{LOS MODOS DE DESOBEDIENCIA}

\subsection{El carácter público y organizado}

Se afirma en ocasiones que la objeción de conciencia se caracteriza también por el hecho de que el objetor da a su acto un carácter público (para provocar el asentimiento o la adhesión de los demás). Pienso que no es un elemento necesario. Por lo pronto, es difícil saber cuándo se sobrepasa el límite de lo privado y se alcanza el ámbito de lo público; pero además, en los casos en los que se hace público, tampoco es fácil de saber cuándo el objetor tenía esa intención. Quizá podamos pensar que normalmente el objetor se ve impulsado a advertir a otros para que no cometan el mismo acto que él considera inmoral, pero no es menos cierto que ni nos negamos a llamar objetor a quien no da publicidad a lo que hace, ni pensamos que sólo lo es el que no lo difunde. Diría que éste es un elemento que no debe formar

\footnotetext{
${ }^{4}$ Así lo sostiene Bobbio: "La desobediencia civil es una forma particular de desobediencia, en la medida en que es ejecutada con el fin inmediato de mostrar públicamente la injusticia de la ley y con el fin mediato de inducir al legislador a cambiarla" (trad. mía) (Bobbio, Matteucci y Pasquino, 1998, p. 335). Ésta es también la posición, por ejemplo, de Soriano (1987, p. 64), Rodríguez-Toubes (1994, p. 167), Falcón (2009, p. 182) o González Vicén (1979, p. 392), quien dice: "La desobediencia civil [...] constituye un instrumento para la reforma o la derogación de una norma o conjunto de normas". Igualmente la de Nino (1989, p. 406), quien sostiene que la objeción de conciencia "se caracteriza por el hecho de que el individuo cree que una obligación jurídica que se le impone está en conflicto con una de sus obligaciones morales...", mientras que la desobediencia civil "consiste en la inobservancia de ciertas normas jurídicas con el fin de lograr, a través de diversos mecanismos, la derogación de esas u otras normas que se consideran moralmente inicuas" (Nino, 1989, p. 407). Y en un sentido similar se expresa Rawls (1995, p. 405) cuando define la desobediencia civil como "un acto público, no violento, consciente y político, contrario a la ley, cometido con el propósito de ocasionar un cambio en la ley o en los programas de gobierno", mientras que la objeción de conciencia "consiste en no consentir un mandato legislativo más o menos directo, o una orden administrativa” (Rawls, 1995, p. 410). Raz (1985, p. 325), en cambio, admite también como objetivo la mera protesta.

${ }^{5}$ Como afirma $\operatorname{Raz}$ (1985, p. 325), no tiene mucho sentido empecinarse en la defensa de una determinada definición, pues, a fin de cuentas, se trata de figuras que se superponen.
} 
parte de la definición, pues en el habla cotidiana no tiene importancia y por su imprecisión puede generar un grado de confusión innecesario ${ }^{6}$. En definitiva, con o sin publicidad, lo que hace el sujeto es básicamente lo mismo. Y así como la intención del sujeto de cambiar el sistema completo sí me parece importante, porque pone en cuestión el elemento de la conciencia (que es el núcleo de la figura), el hecho de que quiera que lo conozcan otros no parece que suponga un cambio sustancial ${ }^{7}$.

Lo mismo se puede decir respecto del carácter organizado, que podría caracterizar la desobediencia civil en contraste con la objeción de conciencia. Tal vez se pueda decir que los motivos esgrimidos en el caso de la desobediencia civil puedan ser más amplios que los de la objeción de conciencia ${ }^{8}$, pero parece más difícil de defender que la mayor o menor organización de la respuesta pueda constituir un límite preciso entre ambas figuras. Podríamos decir, de nuevo, que el hecho de que los objetores se organicen, formen un grupo y presenten una respuesta colectiva parece más un elemento contingente, que no debería formar parte de la definición?.

\subsection{El uso de la violencia}

Suele decirse que la objeción de conciencia excluye el uso de la violencia. Ciertamente, parece haber algo extraño en el hecho de negarse a cumplir con una norma alegando razones morales a través del ataque violento a

\footnotetext{
${ }^{6}$ En el ámbito jurídico español, por ejemplo, ni la Constitución española (art. 30) ni las leyes de desarrollo (48/84 o 22/98) incluyeron referencia alguna a la publicidad. En el ámbito militar, véanse la L.O. 13/91 (d a. 12a) o la ley 17/99 (art. 180).

${ }^{7}$ Véase, por ejemplo Falcón (2009, p. 176). Cosa distinta es que si se acepta que la desobediencia civil tiene como objetivo la derogación de la norma, se entienda entonces que para alcanzar éste más eficazmente se precisa una determinada publicidad (y una determinada organización, como sugiere Arendt (1998, p. 64)), aunque ni siquiera así me parece un elemento necesario. Véase al respecto Rodríguez-Toubes (1994, p. 170).

${ }^{8}$ Aunque ni siquiera esto está claro, como puede verse en Dworkin (1997, p. 304) o en Wellman (1982, p. 30), quien define la desobediencia civil como "una protesta moral", o Casado (2001: 165), quien la define como "un acto motivado por convicciones de conciencia". Falcón (2009, p. 178), por su parte, acepta un motivo moral y otros de carácter político.

${ }^{9}$ Véanse Falcón (2009, p. 179) o Gascón (1990, p. 70), quien afirma que "las dicotomías público-privado o colectivo-individual parecen engañosas [...] [por lo que] no sería correcto atribuir al acto de disidencia una peculiaridad que en el fondo no obedece a la intención del sujeto sino a fenómenos circunstanciales". Por cierto, tampoco Thoreau (1987) sostiene, ni mucho menos, que la desobediencia civil se caracterice por la organización de la respuesta. En contraste pueden verse Bobbio (Bobbio, Matteucci y Pasquino, 1998, p. 337), Soriano (1987: 66) o González Vicén (1979, p. 392), para quien la desobediencia civil "es siempre pública, y por eso también, es susceptible de organización".
} 
personas o cosas. Por supuesto, el contenido de la moral puede ser muy variado, pero tendemos a pensar que la conciencia que se alega en la objeción tiene una base de elementos pacíficos, entre otras cosas porque los deberes que se pretenden incumplir suelen ser entendidos por los objetores como algo violento (coger las armas para adiestrarse en matar a otros o emplear la técnica médica para matar a un feto). Si pensamos, por ejemplo, en la objeción de conciencia al servicio militar, parece difícil de casar la repugnancia a ser adiestrado en la agresividad (con el objetivo de matar a otros) con la aceptación de un género de agresividad similar, contra cosas o personas (con el objetivo de incumplir ese deber). Por otro lado, sin embargo, no exigimos que no aparezca ni un ápice de fuerza, como si sólo fuera posible ejercer la objeción de conciencia al estilo del Bartleby de Melville (2007). No es tan extraño pensar que en algunas ocasiones el objetor puede verse obligado a resistirse a una presión agresiva para que cumpla la norma con algún grado de fuerza. Pero incluso en estos casos lo que aceptamos es una fuerza que se emplea como medio para defender (la conciencia propia) y no como medio para atacar. Diría, pues, que la objeción de conciencia suele entenderse como un ejercicio pacífico que excepcionalmente admite algún grado de violencia, normalmente defensiva ${ }^{10}$.

\section{LA CONCIENCIA FRENTE AL DEBER JURÍDICO}

Como ya hemos indicado, cuando empleamos la expresión 'objeción de conciencia' queremos indicar que un sujeto incumple un determinado deber (es decir, una determinada norma), porque su conciencia le dicta algo incompatible con él y se vería violentada hasta un límite inaceptable. Precisamente porque el fin es salvaguardar su conciencia (y no enfrentarse al sistema), muchos objetores se someten al castigo previsto. El objetor no es quien procura incumplir sus deberes en su beneficio (y por ello oculta lo hecho e intenta evadir el castigo), sino quien quisiera cumplirlos pero se ve obligado a no hacerlo porque su conciencia se lo impide. Su comportamiento es un alegato moral; y es coherente con ello no ocultarse y asumir las consecuencias (bien es cierto que hay también objetores que consideran que no se debe cumplir la norma y que no se debe tampoco aceptar la sanción, porque es inmoral castigar a alguien por negarse a hacer algo

\footnotetext{
${ }^{10}$ En el mismo sentido se pronuncia Wellman (1982, p. 30) cuando se refiere a la desobediencia civil, que, por lo demás, tiene también para él un fundamento moral.
} 
inmoral). No hay que olvidar, no obstante, que la sanción no es la única consecuencia posible del incumplimiento. A veces, desde luego, la norma se cambia y con ella desaparece la sanción y la posibilidad de la objeción. Pero otras veces la sanción desaparece aunque se mantenga el deber porque se acoge la propia objeción de conciencia. En casos así, la objeción se hace norma y el ordenamiento acepta los dos enfoques morales respecto de una determinada cuestión ${ }^{11}$.

Sea lo que sea de esto, lo que importa ahora es considerar la motivación del objetor. ¿A qué nos referimos cuando hablamos de conciencia en este asunto? Por un lado, un concepto demasiado amplio de conciencia nos obligaría a aceptar que cualquiera pudiera incumplir un deber alegando sin más que su conciencia se lo indica asi ${ }^{12}$. Pero no es esto lo que queremos sugerir cuando decimos que alguien es objetor de conciencia; y probablemente calificaríamos de insincero a quien alegara motivos de conciencia en determinados casos. Por otro lado, un concepto demasiado estrecho podría limitar exclusivamente el uso de la objeción y acabar despreciando, y en definitiva vulnerando, la conciencia de algunos sujetos. Y decir que la apelación a la conciencia sólo cabe cuando se trata de cuestiones vinculadas a ella no aclara mucho las cosas.

Desde luego, consideramos que la idea de la conciencia tiene que ver con un determinado planteamiento moral. Y ciertamente pensamos que la objeción a un deber basada en la conciencia es algo positivo. De algún modo, se entiende que hacer valer la conciencia propia frente a una norma jurídica es algo que, en principio, realza el mérito del sujeto. Se trata de alguien que, en términos generales, es un buen ciudadano y cumple con sus deberes, pero que valora tanto su conciencia que frente a un deber que choca con ella prefiere incumplir. Valorar de este modo la conciencia propia es muestra del alto valor y de la solidez moral del sujeto, a pesar de que enfrentarse al Derecho no es algo que se considere valioso, dado que el Derecho (al

\footnotetext{
${ }^{11}$ Confróntese, no obstante, esta idea con la conocida doctrina del Tribunal Constitucional español según la cual no es necesario que exista una regulación específica de la objeción de conciencia pues ésta forma parte del derecho a la libertad ideológica y religiosa proclamado en el art. 16 C.E., que es directamente aplicable (STC 53/85 f.j. 14; STC 145/2015 f.j. 4). Hay también, por cierto, sentencias opuestas que apoyan lo que decimos aquí, como la STC 321/94 (f.j. 4) o la STC 161/87 (f.j. 3), en la que se sostiene que "la objeción de conciencia con carácter general [...] no está reconocid[a] ni cabe imaginar que lo estuviera en nuestro Derecho o en Derecho alguno, pues significaría la negación misma de la idea del Estado".

12 Thoreau (1987, p. 31) tal vez apunte a esto cuando afirma: “¿Debe el ciudadano someter su conciencia al legislador por un solo instante, aunque sea en la mínima medida? [...] La única obligación que tengo derecho a asumir es la de hacer en cada momento lo que crea justo”.
} 
menos en los Estados democráticos) goza de una pretensión de validez, de legitimidad, que desactiva cualquier oposición. Enfrentarse, pues, a un sistema jurídico legítimo sobre la base de que uno piensa de manera diferente es algo destinado a fracasar. Los motivos políticos, por ejemplo, no pueden ser alegados para incumplir una norma porque se entiende que las cuestiones de ideología política entran en el juego de construcción del Derecho, una de cuyas reglas indica que el resultado de ese juego debe ser aceptado por todos. Los motivos de conciencia, sin embargo, se aprecian de otro modo porque se refieren a lo que se considera más importante para los seres humanos, lo que se considera que los constituye, esto es, su moral.

Ahora bien, dicho esto no se puede olvidar tampoco que no todos los planteamientos morales son igualmente aceptados. Para empezar, no se aceptan planteamientos morales que, aunque puedan ser considerados válidos en abstracto, se refieren a asuntos en los que se excluye la objeción (piénsese en las alegaciones morales respecto de los deberes derivados de un determinado sistema económico). Sólo, pues, determinados asuntos se entiende que afectan de forma más directa la conciencia moral de los individuos. Pero, además, ni siquiera sobre todos esos asuntos morales vale cualquier punto de vista. En algunos asuntos, por mucho que pueda darse un conflicto entre la norma que impone el deber y la moral del destinatario, la razón esgrimida por el sujeto no se considera válida y la objeción no es posible porque su conciencia queda deslegitimada (pensemos, por ejemplo, en el que asegura que frente al deber de no matar a otros su conciencia le indica que debe acabar con todos los que no profesan su religión o no comparten su raza). La objeción, por tanto, sólo cabe cuando se acepta que el sujeto tenga un planteamiento moral diferente al que sirve de base a la norma. Se trata de asuntos que se considera que tienen que ver de una manera más clara y directa con el perfeccionamiento personal, en los que el individuo se juega su constitución de persona moralmente recta. Normalmente estas cuestiones se refieren a conductas que dañan o pueden dañar a otros (aborto, eutanasia, servicio militar), pero no siempre es así (matrimonio homosexual). Para algunos individuos, el percibirse como la causa de la muerte de un feto o de un ser humano independiente, o como causa de la legitimación de una unión homosexual, resquebrajaría de tal modo su integridad moral que prefieren no cumplir con sus deberes y mantener esa imagen moral que les hace reconocibles ante sí mismos. Cuando hablamos de la objeción de conciencia nos referimos a la conciencia moral de un individuo respecto de cuestiones que se conciben como fundamentales para 
mantener la propia integridad moral. Y eso es lo que constituye la razón de la desobediencia ${ }^{13}$.

\section{LOS SUJETOS OBJETORES}

Sólo parece posible que exista una conciencia moral en los individuos y no en los grupos de individuos. Desde luego, a veces decimos que un grupo piensa o dice tal o cual cosa, pero se trata de una manera metafórica de hablar. Y es claro que aunque nos entendemos bien así, lo cierto es que sólo los sujetos individuales (y no algo llamado 'grupo') pueden pensar, sentir o decir $^{14}$. Esto es algo que se puede apreciar más claramente en algunos casos, como cuando decimos que un grupo piensa o dice tal o cual cosa, queriendo decir con ello que lo piensan o dicen todos o la mayoría de los miembros de ese grupo tomados individualmente (pensemos en un partido político o en un grupo de aficionados de un equipo de fútbol) o aquella persona que hemos convenido que lo representa. Otras veces, en cambio, lo que queremos decir es que ese grupo (se llame como se llame, persona jurídica, sociedad, asociación, etc.) piensa o dice tal o cual cosa con independencia de lo que piensen aquellos que expresan el pensar del grupo (normalmente el representante), como si hubiera dos pensamientos, el de los miembros individuales del grupo y el del grupo mismo (el de esa cosa llamada 'grupo', que sería algo distinto a sus miembros). No obstante, incluso aquí puede verse que son los individuos, y no algo diferente, los que piensan o hablan. Que el grupo piensa tal cosa significa que ha habido individuos (personas de carne y hueso) que han decidido establecer unas determinadas ideas (referidas, por ejemplo, a principios, valores, metas, etc.) como constitutivas de esa cosa ficticia que han llamado partido, sociedad, asociación o lo que

${ }^{13}$ A ello se refiere Arendt (1998, p. 72) cuando afirma que las normas de la conciencia indican "cuidado con hacer algo con lo que no serás capaz de vivir". Y en un sentido similar se pronuncia Sepper (2012, p. 1528) cuando sostiene que "actuar conforme a la conciencia tiene importancia no tanto porque se refiera a hacer lo moral o políticamente correcto, como porque es fundamental para ser una persona íntegra. La teoría y la práctica enseñan que la conciencia está relacionada estrechamente con la propia integridad moral o sentido de identidad" (trad. mía).

${ }^{14}$ Es algo que ha sido puesto de manifiesto en numerosas ocasiones. Sepper (2012, p. 1539), por ejemplo, lo dice así: "Las personas jurídicas son criaturas del Derecho que no tienen la capacidad de sentir, razonar o actuar sin agentes mediadores". Y añade después, al referirse a las normas que pretendidamente puede definir la moral de una institución que, "puesto que la institución no tiene conciencia ni voluntad, son los individuos los que tienen que interpretar y aplicar cualquier norma o principio a las situaciones concretas" (Sepper, 2012, p. 1542) (trad. mía). 
fuere. Y cuando el representante dice que la institución piensa tal cosa no está describiendo el pensamiento de nadie (como sí haría si dijera el socio número 341 piensa tal cosa), sino dando cumplimiento a esa decisión tomada por individuos. Se crea así una especie de personaje de ficción cuyas características son las que los individuos que lo han creado (y no el personaje) dicen que posee. Y si los individuos deciden fijar esas características y se obligan entre ellos a decir que 'la institución' piensa esto o lo otro, así será (y así seguirá siendo aunque los individuos del grupo sean sustituidos por otros -que mantendrán ese compromiso-). Pero, ciertamente, 'la institución' ni piensa, ni siente, ni habla y, por lo que nos interesa, tampoco es capaz de sentir la motivación de la norma y conformar su conducta a lo que se estipula. Así que cuando la norma se objeta, sólo los individuos pueden tener esa conciencia que sirve de razón para plantear una objeción a un deber, lo que no significa que las ideas o los principios característicos de la institución no importen o no deban ser tomados en consideración.

Todo eso no impide, por supuesto, que se forme una agrupación de individuos que tengan en común, por ejemplo, el hecho de que todos son objetores respecto de determinado asunto (podríamos decir entonces 'el grupo x ejerce la objeción de conciencia respecto a h'). Y también puede ocurrir que sólo se pueda formar parte de tal grupo declarando la objeción (o declarando no tenerla, como podemos pensar que ocurre en el ámbito militar). Un problema diferente será el examinar cuándo se puede producir una situación así; es decir, cuando se permite que entre los requisitos de pertenencia a un grupo esté el que acabamos de mencionar. Pero esto es algo que pertenece al ámbito de los contratos y no nos corresponde analizar aquí. En todo caso, también aquí siguen siendo los individuos (y no el grupo) los que poseen la conciencia; es decir, los que poseen integridad moral y sentimientos ${ }^{15}$.

${ }^{15}$ Lo recuerda también Sepper (2012, p. 1544): "La institución por sí misma no tiene conciencia, sino funciones a través de las cuales varios individuos expresan sus convicciones morales" (trad. mía). Un punto de vista distinto, según el cual sí se puede hablar de una conciencia institucional, es también bien conocido. Véanse, por ejemplo, Beca y Astete (2015, p. 495) o Brown (2006, p. 416), quien considera que las instituciones poseen una conciencia por analogía con la conciencia individual; desde luego, añade, esa conciencia "depende de la conciencia de los que actúan en nombre de la institución” (Brown, 2006, p. 416) (trad. mía), pero eso no significa que no exista o que no se deba tomar en cuenta (incluso más que la individual). La conciencia institucional es, en suma, "la relación de las conciencias de las personas que juzgan o mantienen responsablemente la opinión de una autoridad, acerca de una acción realizada en nombre de la institución” (Brown, 2006, p. 417) (trad. mía). 
Desde luego, se produce un problema cuando el Derecho impone un deber a los individuos y algunos de ellos pertenecen a un grupo que ha establecido como una de sus características la de que sus miembros tienen un deber opuesto a aquél. Se trata de un conflicto de deberes, que tendrá que ser resuelto de algún modo, por ejemplo, dando prioridad al deber más fuerte. Y si el Derecho, que es el sistema donde se insertan los deberes más fuertes, declara que determinadas ideas características del grupo -que se plasman en tales o cuales prácticas- son ilegales (por ejemplo, la esclavización), entonces así será y tales ideas y prácticas tendrán que ser anuladas. Y si permite la objeción de conciencia, entonces podrán los individuos eximirse de su cumplimiento cumpliendo los requisitos establecidos.

\section{LA OBJECIÓN DE CONCIENCIA NORMALIZADA}

Hasta ahora hemos hablado de la objeción de conciencia frente a deberes jurídicos como un argumento que presenta el sujeto obligado, con el que pretende justificar su incumplimiento. Es momento de referirnos a la respuesta que se ofrece desde el Derecho. Dicho básicamente, ésta puede consistir en un desconocimiento o en un reconocimiento de la objeción.

En el primer caso, cuando la objeción no está reconocida por el Derecho, lo que ocurre se puede describir simplemente como un sujeto que incumple su deber y que, en consecuencia, debe recibir la sanción correspondiente. Para constatar la infracción es indiferente que el sujeto incumpla porque su conciencia le incita a ello o que lo haga para cumplir una promesa, por dinero o por ignorancia. Si tenía un deber y no lo cumplió, realizó una conducta antijurídica y debe ser sancionado de acuerdo con lo establecido por la norma en cuestión (la sanción será la que corresponda, dependiendo de las circunstancias atenuantes o eximentes que se prevean con carácter general o específico). En términos generales, si lo único que existe es el deber y la sanción para el que incumple, sólo cabe la acción de cumplir o la alternativa de no cumplir y recibir la sanción; si la objeción de conciencia no está reconocida frente a un determinado deber, no es válida jurídicamente. Ahora bien, dicho esto, no es menos cierto que las alegaciones que el sujeto pueda hacer acerca de su incumplimiento pueden tener una importancia en otros ámbitos, por ejemplo, en el político o en el social. Si el comportamiento del objetor es conocido por otros, puede recibir adhesiones o puede provocar una respuesta social sólida y convertirse en el origen de un instrumento de presión frente a los legisladores. Sea lo 
que sea de esto, lo que interesa ahora destacar es que la validez jurídica de la objeción de conciencia se reconoce cuando así se indica en una norma del sistema. Esto es lo que explica la resistencia a incorporar la objeción de conciencia en términos generales, pues eso supondría aceptar que todos los deberes impuestos por las normas jurídicas podrían ser sometidos a la valoración moral del sujeto obligado y podrían ser dejados de lado.

Cabe, no obstante (este sería el segundo caso) que se reconozca para determinados supuestos. Da igual en estos momentos con qué extensión se haga esto; sea cual sea el detalle de su reconocimiento, el hecho es que el Derecho otorga validez a dicha objeción. En consecuencia, se acepta que un determinado deber pueda ser incumplido cuando el sujeto alega motivos de conciencia ${ }^{16}$. Cuando esto es así, sólo cabe ejercer la objeción y exonerarse del deber en los supuestos, en los momentos, de los modos y por los sujetos que la norma jurídica indica. Es la norma jurídica la que constituye la objeción y por lo tanto es ella la que establece sus características y sus límites. En otros términos, los comportamientos que no cumplen con lo estipulado por la norma que regula la objeción se tratan conforme a lo dicho en el párrafo anterior.

Y aquí pueden considerarse dos situaciones. En algunos casos, el incumplimiento del sujeto no afecta directamente a nadie más. Se da esta situación cuando la norma en cuestión le impone al sujeto un comportamiento que no repercute sobre nadie, un comportamiento que no consiste en hacer (o no hacer) algo a (o para) nadie. Pensemos, por ejemplo, en el deber de hacer el servicio militar. Desde luego hay sujetos involucrados en el caso (lo contrario sería difícil), pero entendemos que el hacer el servicio militar no consiste en 'hacer algo a otro'. Puede decirse entonces que el incumplimiento no produce ningún perjuicio directo a otro. No obstante, sí se plantea un problema de discriminación en relación con los sujetos que cumplen, que es particularmente notorio cuando se entiende que el deber que se impone no es algo especialmente agradable. Esta discriminación estaría amparada por el Derecho, que estaría tratando de manera desigual a los individuos obligados, sobre la base de la objeción. Alegando motivos de conciencia, unos estarían exonerándose de un deber poco grato, mientras que los demás se verían obligados a cumplir. Atendiendo a esta circunstancia es por lo que se constituye otro deber de similares características para todo aquellos

\footnotetext{
${ }^{16}$ Como afirma Ruiz Miguel (1996, p. 105), "la objeción de conciencia jurídicamente reconocida presupone la existencia de un deber legal genérico cuya exención personal por razones morales por parte de algunos de sus destinatarios es también aceptada jurídicamente".
} 
que no desean cumplir el primero (en el caso del servicio militar en España, lo que se denominó prestación social sustitutoria), evitando así que la conciencia ( $\tan$ difícilmente fiscalizable) se convierta en una vía de escape para eludir una tarea poco deseada impuesta por el Derecho.

En otros casos, puede ocurrir que el deber del sujeto obligado recaiga sobre un tercero y por tanto su incumplimiento tenga efectos directos e inmediatos sobre otro; esto es lo que sucede cuando el deber consiste en hacer (raramente en no hacer) algo a (o para) un tercero, como ocurre, por ejemplo, en los casos de aborto ${ }^{17}$. Puede tratarse de un deber no derivado, esto es impuesto directamente por la norma, o de un deber derivado (del ejercicio de un derecho de otro). Sea el deber que sea, lo cierto es que en ocasiones el individuo se ve obligado a hacer algo que tiene una repercusión directa en otro, algo que le beneficia. Siendo esto así, cuando el sujeto no cumple con su deber, el tercero que debía verse beneficiado por ese comportamiento se ve, en cambio, perjudicado. Este perjuicio del tercero beneficiario es el que se intenta evitar cuando se obliga al objetor a tomar las medidas oportunas para que el deber que él incumple pueda ser cumplido por otro.

\section{REFERENCIAS}

Aparisi, Á. y López, J. (2006). “El derecho a la objeción de conciencia en el supuesto de aborto". Persona y Bioética, 10(1), 35-51.

Arendt, H. (1998). Crisis de la república. Madrid, España: Taurus.

Beca, J. P. y Astete, C. (2015). "Objeción de conciencia en la práctica médica". Revista Médica de Chile, 153, 493-498.

Bobbio, N., Matteucci, N. y Pasquino, G. (1998). Dicionário de política. Brasilia, Brasil: Editora Universidade de Brasilia.

Brown, G. T. (2006). "Institutional Conscience and Catholic Health Care". Life and Learning, XVI, 413-423. Recuperado de http://www.uffl.org/pastproceedings.html

Casado da Rocha, A. (2001). "Relativismo ético y desobediencia civil". Thémata, 27, 165-171.

Dworkin, R. (1997). Los derechos en serio. Barcelona, España: Ariel.

Falcón y Tella, M. J. (2009). “Objeción de conciencia y desobediencia civil: similitudes y diferencias". Anuario de Derechos Humanos, 10, 171-182.

Garzón, E. (1981). “Acerca de la desobediencia civil”. Sistema, 42, 79-92.

\footnotetext{
${ }^{17}$ Se da el caso de un deber de no hacer, por ejemplo, como recuerda Triviño (2014, p. 107), cuando se prohíbe dar asistencia sanitaria a las personas que no tienen la documentación pertinente (los llamados 'sin papeles').
} 
Gascón, M. (1990). Obediencia al Derecho y objeción de conciencia. Madrid, España: Centro de Estudios Constitucionales.

González Vicén, F. (1979). "La obediencia al Derecho". Estudios de filosofía del Derecho. La Laguna: Facultad de Derecho, 365-398.

López Zamora, P. (2002). "Análisis comparativo entre la desobediencia civil y la objeción de conciencia”. Anuario de Derechos Humanos, 3, 317-335.

Malem, J. (1988). Concepto y justificación de la desobediencia civil. Barcelona, España: Ariel.

Melville, H. (2007). Bartleby, el escribiente, Benito Cereno, Billy Budd. Madrid, España: Tecnos.

Nino, C. S. (1989). Ética y derechos humanos. Barcelona, España: Ariel.

Ortega, D. (1999). "La objeción de conciencia en el ámbito sanitario". Revista de Derecho Político, 45, 105-147.

Passerin, A. (1976). "Legitimidad y resistencia". Sistema, 13, 27-34.

Rawls, J. (1995). Teoría de la justicia. Madrid, España: Fondo de Cultura Económica.

Raz, J. (1985). La autoridad del Derecho. México, D.F. México: Editorial UNAM.

Rodríguez-Toubes, J. (1994). "Sobre el concepto de objeción de conciencia". Direito, $\operatorname{III}(2), 159-186$.

Ruiz Miguel, A. (1996). "La objeción de conciencia a deberes cívicos”. Revista Española de Derecho Constitucional, 47, 101-124.

Sepper, E. (2012). “Taking Conscience Seriously”. Virginia Law Review, 98(7), 1501-1575.

Soriano, R. (1987). “La objeción de conciencia: Significado, fundamentos jurídicos y positivación en el ordenamiento jurídico español”. Revista de Estudios Políticos, 58, 61-110.

Thoreau, H. D. (1987). Desobediencia civil. Madrid, España: Tecnos.

Triviño, R. (2014). El peso de la conciencia. Madrid, España: CSIC-Plaza y Valdés.

Wellman, C. (1982). Morales y éticas. Madrid, España: Tecnos. 